\title{
Physicochemical compatibility studies of triclosan and flurbiprofen with excipients of pharmaceutical formulation using binary, ternary, and multi-combination approach
}

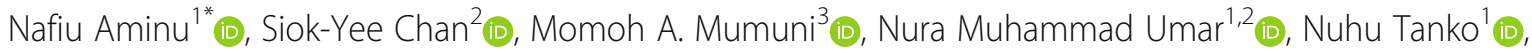 \\ Sirajo Abubakar Zauro ${ }^{4}$, Abdulmalik Aminu ${ }^{5}$ (i) and Seok-Ming Toh ${ }^{2}$ (i)
}

\begin{abstract}
Background: The aim of the study was to evaluate the suitability of triclosan (TCS) and flurbiprofen (FLB) with poly$\varepsilon$-caprolactone (PCL), chitosan (CS), and Kolliphor ${ }^{\otimes}$ P188 (KP) for possible application in the design of nanoformulations.

Results: Differential scanning calorimetry (DSC), X-ray powder diffraction (XRPD), and scanning electron microscopy (SEM) revealed the physical characteristics of the various sample compositions without any apparent interaction. The Fourier transform infrared spectroscopy (FTIR)'s spectra of the physical mixtures showed their characteristic absorption bands with broadening and overlapping of bands in some instances, but no appearance of new bands was observed.

Conclusion: The study revealed the physical form stability of the evaluated components after the storage period and lack of definite pharmaceutical incompatibility between them. Thus, the selected drugs and excipients could be used for the development of pharmaceutical nano-formulations.
\end{abstract}

Keywords: Triclosan, Flurbiprofen, Compatibility studies, Poly-ع-caprolactone, Chitosan, Drug-Excipient

\section{Background}

Development of a rational and ideal pharmaceutical product should encompass the preformulation study of the active pharmaceutical ingredients (APIs) against its intended formulation excipients. Preformulation is an investigation carried out during drug product development to assess physicochemical properties of the drug candidate, either alone or in combination with excipients for effective drug delivery [1-5]. Preformulation helps generate useful information as per the API, excipient, formulation parameters, and delivery method to guide the

\footnotetext{
* Correspondence: nafiu.aminu@udusok.edu.ng; nabgus@yahoo.com 'Department of Pharmaceutics and Pharmaceutical Microbiology, Faculty of Pharmaceutical Sciences, Usmanu Danfodiyo University, P.M.B, Sokoto 2346, Nigeria

Full list of author information is available at the end of the article
}

formulation scientists to develop an efficient and stable dosage form. Importantly, detection of incompatibilities between excipients and the active medicament represents a vital and integral part of the preformulation, and therefore, must be conducted at the early stage of drug product development [6-8]. In a drug formulation, the active molecules and excipients may interact during the processing stage and consequently, may affect the chemical nature, quality, stability, therapeutic efficacy, bioavailability, and safety profile of the final product [9-13].

Incompatibility between an API and excipient may arise from hydrogenation, hydrolysis, photodegradation, oxidation, dehydration, elimination, isomerization, cyclization, ionic complexation, and denaturization [14]. Hydrogenation reactions may occur via hydrogen-donating functional groups of an API, resulting in drug-excipient 
interaction [15]. Ionic interactions may occur in solution between counter ions brought by ionizable and soluble excipients and ionizable API, resulting in insoluble products [15-17]. Many factors such as $\mathrm{pH}$, temperature, light, oxygen, and moisture act as catalysts for initiating the drugsexcipients incompatibility reaction [14]. Based on the aforementioned facts, it becomes very imperative to evaluate any possible incompatibility that may arise from any new formulation design.

Till date, there is no clear cut as per the universally accepted protocol for drug-drug or drug-excipient compatibility testing $[7,15,18,19]$. However, the simple and most commonly employed procedure for this purpose is combining the drug substance with the excipient(s) that are intended for the formulation to form a binary, ternary, or multiple-component physical mixture systems, with or without moisture, and their subsequent storage under normal or stress conditions for a specific period $[7,20,21]$. This is usually followed by evaluations using various analytical techniques such as differential scanning calorimetry (DSC), Fourier transform infrared spectroscopy (FTIR), X-ray powder diffraction (XRPD), highperformance liquid chromatography (HPLC), scanning electron microscopy (SEM), etc., to estimate the potential incompatibilities, degradation pathways, and impurities [14, 21-24]. The DSC or other rapid thermal analysis technique like thermogravimetry can detect possible physical interactions [25, 26]. DSC can reveal drugexcipient interactions through the endothermal or exothermal effects, by the appearance, shift, or disappearance of thermogram peak(s) $[25,27]$.

Similarly, complementary techniques such as XRPD and SEM are commonly employed as a supplement of DSC study [21]. FTIR and nuclear magnetic resonance (NMR) are also being employed to study incompatibilities of drug-excipient physical mixtures, especially for the detection of any possible chemical interactions [7, 9]. Other analytical techniques such as HPLC and liquid chromatography-mass spectrometry are used to detect impurities through evaluation of the peaks and the elution time [6, 28-30]. Various researchers have recently reported compatibility studies for the physical mixtures of drugs-excipients in 1:1 ratio, using these analytical techniques [31-33].

The present study investigates compatibility screening based on binary or multiple combination mixtures of the drugs, i.e., triclosan (TCS) and flurbiprofen (FLB), with

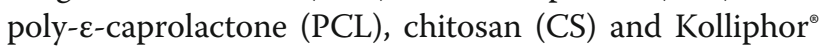
P188 (KP) as the excipients. The physical forms of the selected components where reported as crystalline powder for TCS and FLB [34], semi-crystalline for PCL [35, $36]$ and KP [37], and amorphous for CS [20, 38, 39]. However, we could not find any reported data for the effects of storage under specified conditions, on the physical stability of these components, and hence, it is desirable to provide this data.

A suitable formulation of TCS and FLB combination would be highly desirable for periodontal therapy, owing to the therapeutic efficacy of the drugs. TCS is a broadspectrum antimicrobial agent with a recognized efficacy against several plaque-forming bacteria and has been used extensively in various products for many decades [40, 41]. Studies have shown that the broad-spectrum antimicrobial effect of TCS covered a wide range of Gram-positive and Gram-negative bacteria found in the oral cavity $[42,43]$. On the other hand, FLB belongs to non-steroidal anti-inflammatory drugs (NSAIDs) class of drugs that has been well investigated during the last two decades, as a modulator of the inflammatory response of the host having periodontitis $[44,45]$. Studies have revealed evidence which indicated that supplementing periodontitis treatment with NSAIDs can have a positive effect on the outcome of the therapy [44, 46-51]. Looking at these potential benefits of TCS and FLB, it is worthwhile to establish a compatibility profile of their combination for the design of formulation that can be used to treat oral cavity diseases such as periodontitis. The objective of this study was to evaluate possible incompatibilities/interaction between drug-drug, drugexcipient, drugs-excipients, and excipient-excipient for possible nano-formulation design, using DSC, HPLC, XRPD, and FTIR techniques. The present study also employed these techniques to provide data for the effect of storage of TCS, FLB, PCL, CS, and KP at ambient temperature, on their respective physical forms.

\section{Methods}

\section{Chemicals and reagents}

Triclosan was purchased from Bio Basic Canada Inc. (Markham Ontario, Canada). Flurbiprofen was from FDC Limited (Mumbai, India). Potassium bromide, acetonitrile, and methanol of HPLC grade were purchased from Merck Darmstadt, Germany. Chitosan with a molecular weight of 190-310 kDa and degree of deacetylation of $85 \%$, poly- $\varepsilon$-caprolactone, and Kolliphor ${ }^{\circ}$ P188 were purchased from Sigma-Aldrich, USA. Distilled water was produced in-house by the Favorit W4L water system (Genristo Ltd, England). All reagents and chemicals were of analytical grade.

\section{Samples preparations and compatibility study}

Binary, ternary, or multi-combination mixtures of drugdrug, drug-excipient, drugs-excipients, or excipientexcipient were prepared in 1:1 $(w / w)$ ratios as presented in Table 1. Briefly, the samples were weighed accordingly, mixed to form physical mixtures, uniformly comminuted with a mortar and pestle, and then transferred into airtight light-resistant glass containers $(6 \mathrm{~cm}$ height 
Table 1 Individual drugs and excipients and their physical mixtures for compatibility study. The assay results indicated recoveries of drugs only

\begin{tabular}{|c|c|c|c|}
\hline S/No. & Sample & Drug content (\% recovery), $\pm S D, n=3$ & $\%$ RSD \\
\hline 1 & TCS & $100.30 \pm 1.54$ & 0.60 \\
\hline 2 & FLB & $99.65 \pm 2.06$ & 0.12 \\
\hline 3 & $\mathrm{PCL}$ & - & - \\
\hline 4 & CS & - & - \\
\hline 5 & KP & - & - \\
\hline 6 & $\mathrm{TCS}+\mathrm{FLB}$ & $101.49^{a} \pm 0.80^{a} \& 99.71^{b} \pm 1.19^{b}$ & $0.16^{a} \& 0.33^{b}$ \\
\hline 7 & $P C L+C S+K P$ & - & - \\
\hline 8 & $\mathrm{TCS}+\mathrm{PCL}$ & $97.73^{\mathrm{a}} \pm 2.72^{\mathrm{a}}$ & $1.61^{\mathrm{a}}$ \\
\hline 9 & $\mathrm{TCS}+\mathrm{CS}$ & $100.27^{\mathrm{a}} \pm 1.22^{\mathrm{a}}$ & $0.56^{\mathrm{a}}$ \\
\hline 10 & $\mathrm{TCS}+\mathrm{KP}$ & $101.83^{\mathrm{a}} \pm 1.55^{\mathrm{a}}$ & $0.98^{\mathrm{a}}$ \\
\hline 11 & $F L B+P C L$ & $97.04^{b} \pm 2.18^{b}$ & $1.38^{\mathrm{b}}$ \\
\hline 12 & $F L B+C S$ & $98.11^{b} \pm 4.05^{b}$ & $0.32^{b}$ \\
\hline 13 & $F L B+K P$ & $100.01^{b} \pm 0.79^{b}$ & $0.64^{b}$ \\
\hline 14 & $\mathrm{TCS}+\mathrm{FLB}+\mathrm{PCL}+\mathrm{CS}+\mathrm{KP}$ & $98.37^{\mathrm{a}} \pm 3.50^{\mathrm{a}} \& 98.74^{\mathrm{b}} \pm 0.76^{\mathrm{b}}$ & $1.20^{\mathrm{a}} \& 0.47^{\mathrm{b}}$ \\
\hline
\end{tabular}

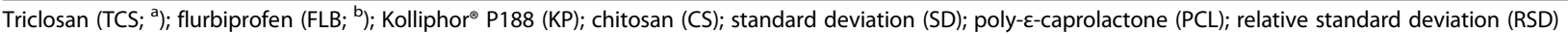

$\times 2.5 \mathrm{~cm}$ diameter). To ensure homogeneity and even particle size distribution, each mixture was adequately grounded and passed through sieve number 120 (125 $\mu \mathrm{m})$ and subsequently observed under optical microscope before its transfer into the container. In the case of PCL, which comes as hard pellets, a laboratory mill (mrc, UK) was used to size reduced it to fine particles before mixing with the other component. The physical mixtures in the containers were stored at ambient temperature for 30 days. The individual pure drugs and excipients were also stored separately under the same conditions of the physical mixtures to serve as controls. The prepared samples were characterized using DSC, XRPD, and FTIR. The HPLC analysis was performed to validate the samples through the elution times and the ordinate of peaks. SEM was conducted to examine the polymorphic forms of the drugs.

\section{Samples characterizations Differential scanning calorimetry}

DSC analyses of the individual pure drugs and excipients and their physical mixtures were conducted using differential scanning calorimeter (Pyris 6 DSC, Perkin Elmer, The Netherland). Briefly, the DSC system was previously calibrated using pure indium. About 3-5 mg of samples were weighed in aluminum pans (Perkin Elmer), sealed using Perkin Elmer DSC sealer, and then analyzed against a reference empty aluminum pan. The analysis was carried out under nitrogen purging, flowing at 20 $\mathrm{mL} \mathrm{min}{ }^{-1}$ and at a heating rate of $10{ }^{\circ} \mathrm{C} \mathrm{min}{ }^{-1}$ over a temperature range of $20-300{ }^{\circ} \mathrm{C}$. The thermograms were analyzed by Pyris software (Perkin Elmer).

\section{Fourier transform infrared spectroscopy}

FTIR analysis of each pure drug, pure excipient, and their physical mixtures were performed using a Thermo Nicolet NEXUS 470 FTIR spectrometer (Thermo Fisher Scientific Inc., USA). The machine was equipped with a deuterated triglycine sulfate detector. The detector was fitted with a potassium bromide $(\mathrm{KBr})$ window. Each FTIR sample was prepared by compressing a uniform mixture of about $1 \mathrm{mg}$ of solid sample and $100 \mathrm{mg}$ of $\mathrm{KBr}$ (IR spectroscopy grade) using a hydraulic press (Beckman ${ }^{\circ}$, USA) to form a thin pellet. The spectra were recorded using the $\mathrm{KBr}$ pellets over a range of $4000-400$ $\mathrm{cm}^{-1}$, with a resolution of $4 \mathrm{~cm}^{-1}$. The data acquisition and interpretation were conducted using $\mathrm{OMNIC}^{\bullet}$ software version 9.2.86 (Thermo Fisher Scientific Inc., USA).

\section{Scanning electron microscopy}

To assess the solid-state of the pure drugs, their surface morphology were investigated using a Leo Supra 50 VP field emission scanning electron microscope (Carl-Ziess SMT, Oberkochen, Germany). The machine was operated under high vacuum mode at an accelerating voltage of $10-15 \mathrm{kV}$, and it was attached to an Oxford Inca-X energy dispersive X-ray microanalysis system (Oxford Instruments, UK). Prior to the analysis, the samples were mounted on a brass stage using double-sided adhesive carbon tape and then sputter-coated (Polaron SC515 sputter coater, Fison instruments, Sussex, UK) with gold-palladium alloy to enable electric conductivity. The surface morphology of the samples was recorded at different magnifications by SEM software (Oxford Instruments, UK). 


\section{$X$-ray powder diffraction}

A Bruker X-ray diffractometer D8 Advance (Karlsruhe, Germany) was used to perform the XRPD analysis in order to investigate the effect of the binary and multicombination mixtures of drugs-excipients on the crystallinity of the drugs. The machine was equipped with a copper X-ray tube and a flat-plate sample holder. The sample powders were irradiated with X-ray beam (wavelength $=1.54060 \AA$ ) with an applied voltage and current of $40 \mathrm{kV}$ and $40 \mathrm{~mA}$, respectively. All measurements were performed under the run time of $25.5 \mathrm{~min}$ and over diffraction angle (2 Theta) range of $1.5^{\circ}$ to $50^{\circ}$, at a scanning rate of $0.020^{\circ} 2$ Theta/step size. The XRPD patterns of pure drugs, pure excipients, a physical mixture of drugs, and physical mixtures of drugs-excipients were recorded and interpreted using the Bruker's Diffrac.suite eva software (Karlsruhe, Germany).

\section{High-performance liquid chromatography analysis}

HPLC analysis was conducted for the samples containing APIs only, to determine the drug content after the 30 days of storage. For sample preparation, an amount of each sample containing nominal API content equivalent to 2 mg was dissolved in methanol up to $20 \mathrm{~mL}$. The mixture was vortexed for $2 \mathrm{~min}$ and then centrifuged at 10,000 $\mathrm{rpm}$ for $20 \mathrm{~min}$. The supernatant was filtered through a $0.45 \mu \mathrm{m}$ polytetrafluoroethylene membrane syringe filter and then analyzed using our previously developed HPLC method [52-54]. Briefly, the HPLC analysis was performed using a Shimadzu (Japan) HPLC system. For the chromatographic separations, an Agilent column, ZORBAX SB-C18 $(5 \mu \mathrm{m}, 4.6 \times 250 \mathrm{~mm})$ (USA) was used at a set temperature of $30{ }^{\circ} \mathrm{C}$. The mobile phase was a mixture of acetonitrile and $0.001 \mathrm{M}$ citric acid $(\mathrm{pH} 3)$, at a ratio of 90:10, $v / v$, respectively. The flow rate was set at $0.3 \mathrm{~mL}$ $\mathrm{min}^{-1}$ under isocratic elution mode. Injection volume of the sample solutions was $10 \mu \mathrm{L}$, and for each injection, a run time of $20 \mathrm{~min}$ was allowed. All the mobile phase used for the analysis was filtered through a nylon filter $(0.45$ $\mu \mathrm{m})$ containing a titan membrane disc (Sun Sri, USA) and degassed using Power Sonic 405 sonicator (Seoul, Korea) prior to their use.

\section{Results}

\section{Visual observations}

There were no significant visual changes observed in the samples as per the organoleptic parameters (color, texture, or gas formation) during and after the storage period.

\section{Differential scanning calorimetry}

DSC thermograms of each selected drug, excipient, and the combined physical mixture of all components are shown in Fig. 1. The initial main thermal event registered in all samples was an endothermic peak in the range of 53 to $114{ }^{\circ} \mathrm{C}$. TCS, FLB, and KP exhibited endothermic peaks at $58.1{ }^{\circ} \mathrm{C}, 114.3{ }^{\circ} \mathrm{C}$, and $53.6{ }^{\circ} \mathrm{C}$, respectively. These sharp melting peaks corresponded with enthalpy or heat of fusion $\left(\Delta H_{\text {fus }}\right)$ of $62.3,76.9$, and 93.9 $\mathrm{J} \mathrm{g}^{-1}$ for TCS, FLB, and KP, respectively. The endothermic melting peak of PCL was at $63.1^{\circ} \mathrm{C}$ while that of CS stretched between 29 and $98{ }^{\circ} \mathrm{C}$.

The melting endotherms of TCS, KP, and PCL were slightly broadened, overlapped, and shifted toward the lower temperature range (starting from $42.4{ }^{\circ} \mathrm{C}$ and ending at $52.1^{\circ} \mathrm{C}$ ) which arose merely because of mixing effect of the components [55]. The melting peak of FLB was not detected in the drugs-excipients physical mixture. Similar thermal events were observed in 1:1 physical mixtures of FLB + KP, TCS + PCL, and TCS + KP, with the disappearance of FLB melting peak in FLB and KP combination (Fig. 2A), and broadening and/or shifting of melting peaks toward the lower temperatures in the case of TCS + PCL and TCS + KP, as shown in Fig. $2 \mathrm{~B}$ and $\mathrm{C}$, respectively. However, no extra endothermic peaks could be observed to indicate any possible incompatibility in all these thermograms.

For the 1:1 $w / w$ physical mixture of the drug substances, the melting peaks were a simple superimposition (Fig. 3). However, a decrease in the onset temperature ( $T_{\text {onset }}$ ) from 111.8 to $78.5^{\circ} \mathrm{C}$ and broadening of melting peak was observed in the case of FLB (Fig. 3) which could be associated with partial miscibility between the two drugs due to the mixing [28, 55].

TCS and FLB exhibited another broad endothermic peak at 236 and $249{ }^{\circ} \mathrm{C}$, respectively (Fig. 3), which could be assigned to their structural decomposition at these temperatures.

The DSC curve of a ternary physical mixture of selected excipients (KP, PCL, and CS) showed sharp and reasonably sharp endothermic peaks at 52.5 and $62.8{ }^{\circ} \mathrm{C}$ corresponding to the characteristic endotherms of pure KP and PCL, respectively (Fig. 4). In the case of CS, no endothermic peak was observed, probably due to its amorphous nature. This suggested that the selected excipients are compatible with each other.

In the DSC curves of 1:1 w/w physical mixtures of TCS $+\mathrm{CS}, \mathrm{FLB}+\mathrm{CS}$, and FLB + PCL, as shown in Fig. 5A, B, and $C$, respectively, all the endothermic melting peaks of the components were well preserved and matched their respective pure component. The characteristic endotherms of each component have appeared in these mixtures, thus demonstrating lack of physical interactions. As indicated in Fig. $5 \mathrm{C}$ for the physical mixture of FLB + PCL, the area and $\Delta H_{\text {fus }}$ of the endothermic melting peak of FLB significantly decreased from 346.2 to $9.3 \mathrm{~mJ}$ and 76.9 to $1.2 \mathrm{~J} \mathrm{~g}^{-1}$, respectively. These changes in the endotherm melting peak may be due to the mixing process. 


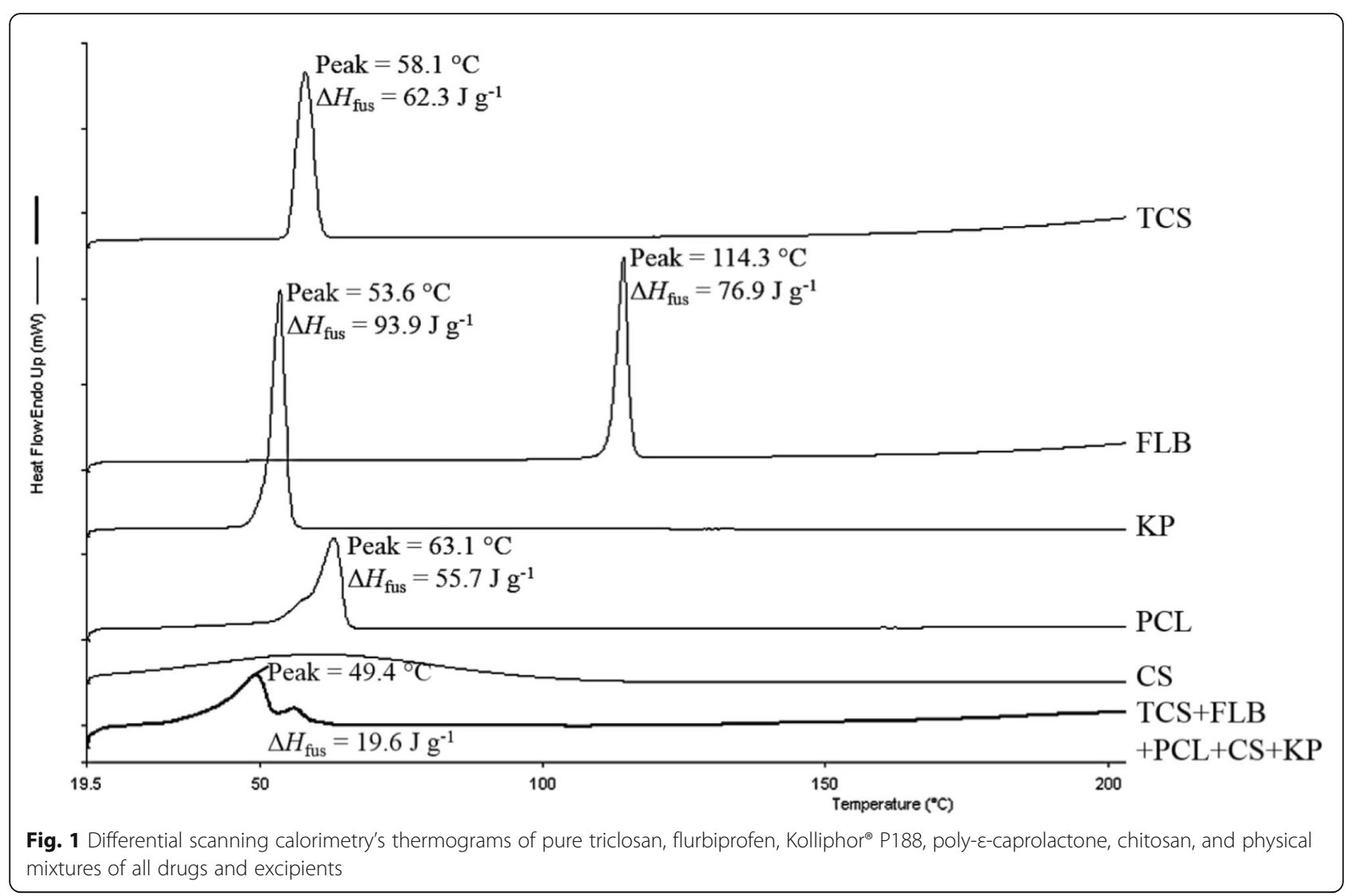

Although most of the thermal events of the physical mixtures of the selected drugs and excipients did not show any evidence of pharmaceutical incompatibility, some physical mixtures suggested the possibility of solid-state interaction, hence the need for further studies to corroborate this findings.

\section{Fourier transform infrared spectroscopy}

The 1:1 $w / w$ physical mixture of the drugs revealed that their FTIR spectra are a simple superimposition and their original bands were well preserved (Fig. 6).

The TCS spectrum exhibits the characteristic absorption bands at 1599, 1578, 1508, 1470, 1413, and 1351 $\mathrm{cm}^{-1}$ which mostly appeared as a pair of bands corresponding to $\mathrm{C}=\mathrm{C}$ stretching of the aromatic ring vibrations [56]. The $\mathrm{C}-\mathrm{H}$ stretching of TCS that occurred above $3000 \mathrm{~cm}^{-1}$ indicated the multiplicity of weak bonds, and the additional peaks at 910 and $857 \mathrm{~cm}^{-1}$ represent $\mathrm{C}-\mathrm{H}$ bending [57]. The characteristic strong phenol group $(\mathrm{O}-\mathrm{H})$ stretching peak of TCS was observed as broadband at $3313 \mathrm{~cm}^{-1}$, while those between 1200 and $950 \mathrm{~cm}^{-1}$ were for $\mathrm{C}-\mathrm{O}$ stretching [18]. The noted peak of TCS at $754 \mathrm{~cm}^{-1}$ was assigned to the C$\mathrm{Cl}$ stretching bond $[57,58]$. These observed bands were also reflected in the spectrum of the physical mixture of TCS and FLB. On the other hand, the FLB spectrum shows characteristic sharp peaks at $1708 \mathrm{~cm}^{-1}$ and 1212 $\mathrm{cm}^{-1}$ corresponding to stretching of $\mathrm{C}=\mathrm{O}$ and $\mathrm{C}-\mathrm{F}$, respectively, and characteristic broad vibrations in the fingerprint region of $3200-2500 \mathrm{~cm}^{-1}$ due to hydrogen bonding $[59,60]$. These bands were also present in the spectrum of blends of the drugs. The benzene ring $(\mathrm{C}=$ C) vibrations of FLB between 1580 and $1200 \mathrm{~cm}^{-1}$ was also noted. The vibrations at the lower frequencies in the deformational region were observed in both drugs' spectrum in their pure and combined forms (Fig. 6). The small $\mathrm{C}-\mathrm{H}$ stretching at $2948 \mathrm{~cm}^{-1}$ observed in the spectrum of pure TCS was not seen in the spectrum of the physical mixture of the drugs which may be due to the formation of weak intermolecular hydrogen-bonding with FLB.

The FTIR spectra of the physical mixtures of FLB + KP, FLB + PCL, TCS + PCL, and TCS + KP are presented in Fig. 7.

The spectra of the selected excipients displayed their characteristic absorption vibrations in the region between 3600 and $2700 \mathrm{~cm}^{-1}$ due to $\mathrm{C}-\mathrm{H}$ and $\mathrm{O}-\mathrm{H}$ stretching vibrations, with a strong broadband at 3430 $\mathrm{cm}^{-1}$ in the case of CS, because of the additional stretching vibrations from $\mathrm{N}-\mathrm{H}$ bonds $[18,20]$. The characteristic strong absorbance peaks of PCL between 3000 and $2800 \mathrm{~cm}^{-1}$ and at $1728 \mathrm{~cm}^{-1}$ due to aliphatic $\mathrm{CH}_{2}$ and 

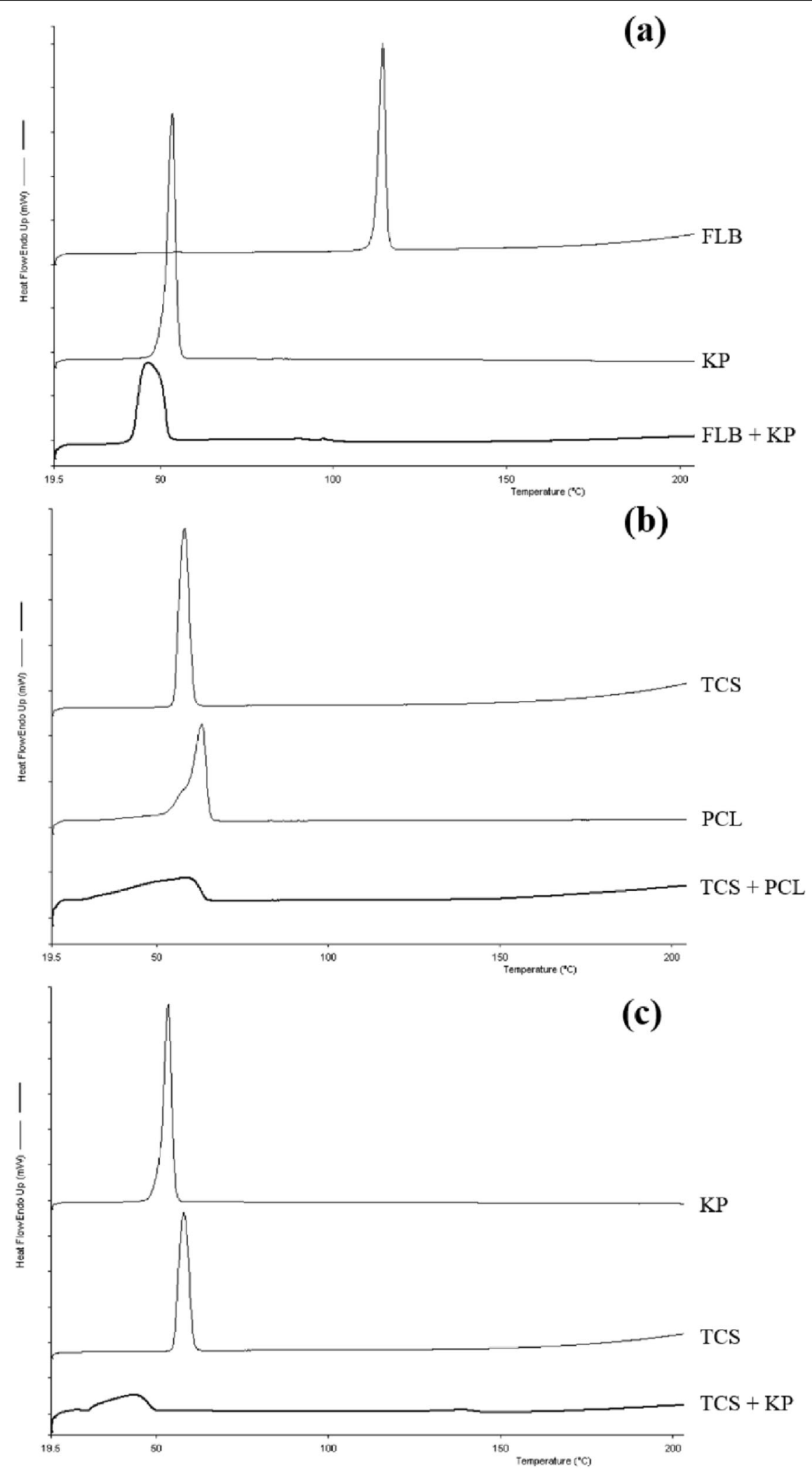

Fig. 2 Differential scanning calorimetry's thermograms of 1:1 w/W combinations of a flurbiprofen with Kolliphor ${ }^{\circledast} 188, \mathbf{b}$ triclosan with poly- $\varepsilon-$ caprolactone, and $\mathbf{c}$ triclosan with Kolliphor ${ }^{\oplus}$ P188, along with their respective individual pure components for comparison 


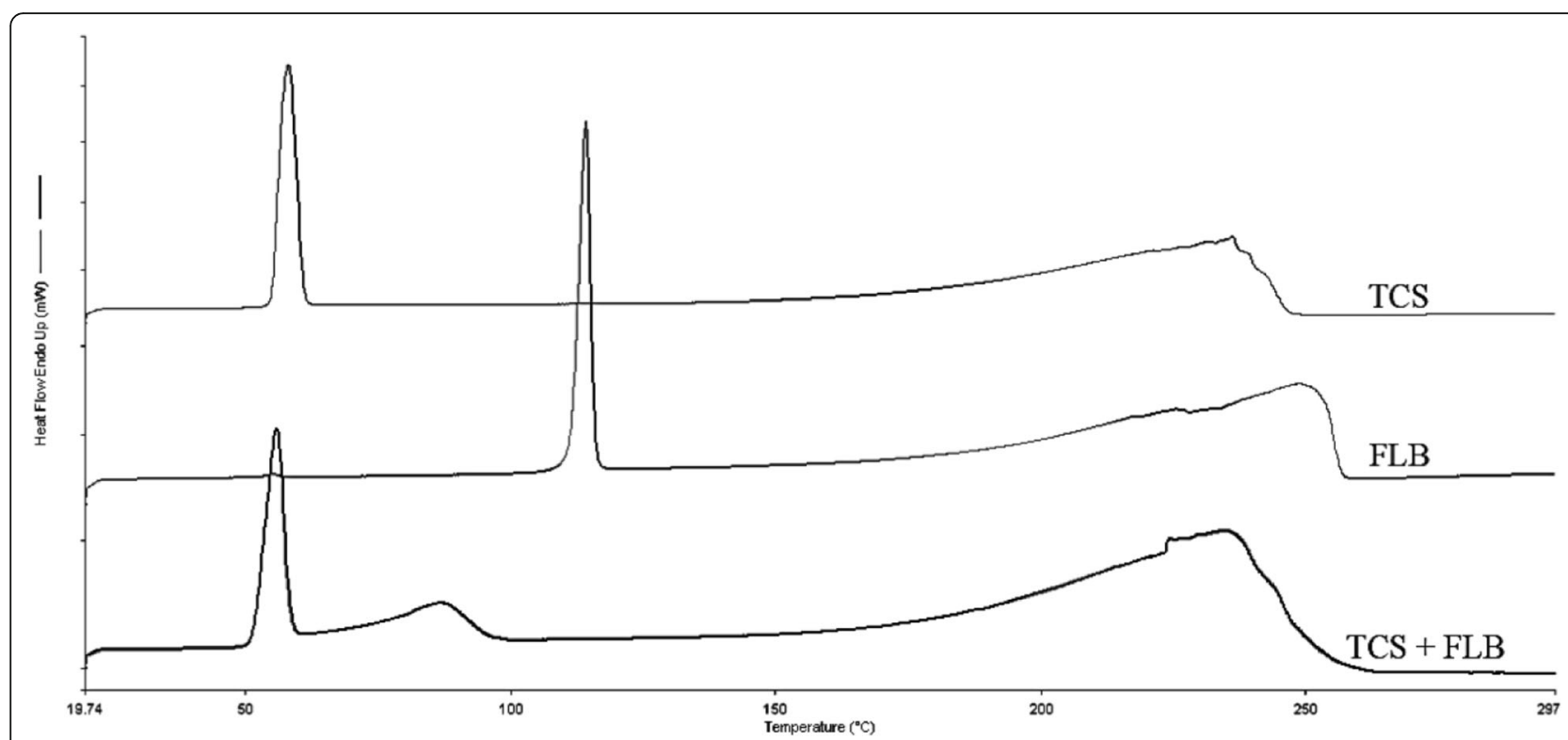

Fig. 3 Differential scanning calorimetry's thermograms of pure triclosan (TCS), flurbiprofen (FLB), and their 1:1 physical mixture

carbonyl group $(\mathrm{C}=\mathrm{O})$ stretching, respectively, were noted in the spectra of pure PCL and combination forms. KP shows a prominent broad absorption band at $3494 \mathrm{~cm}^{+1}$ due to polymeric $\mathrm{O}-\mathrm{H}$ stretching and other peaks between 3000 and $2700 \mathrm{~cm}^{-1}$ and at 1474 due to aliphatic $\mathrm{CH}_{3}$ and $\mathrm{CH}_{2}$ stretching and $\mathrm{C}-\mathrm{O}-\mathrm{C}$ stretching, respectively [61]. Interestingly, most of these observed peaks in the individual pure excipients have also appeared in their mixtures with co-excipients and drugs, as displayed in Fig. 7 and Fig. 8.

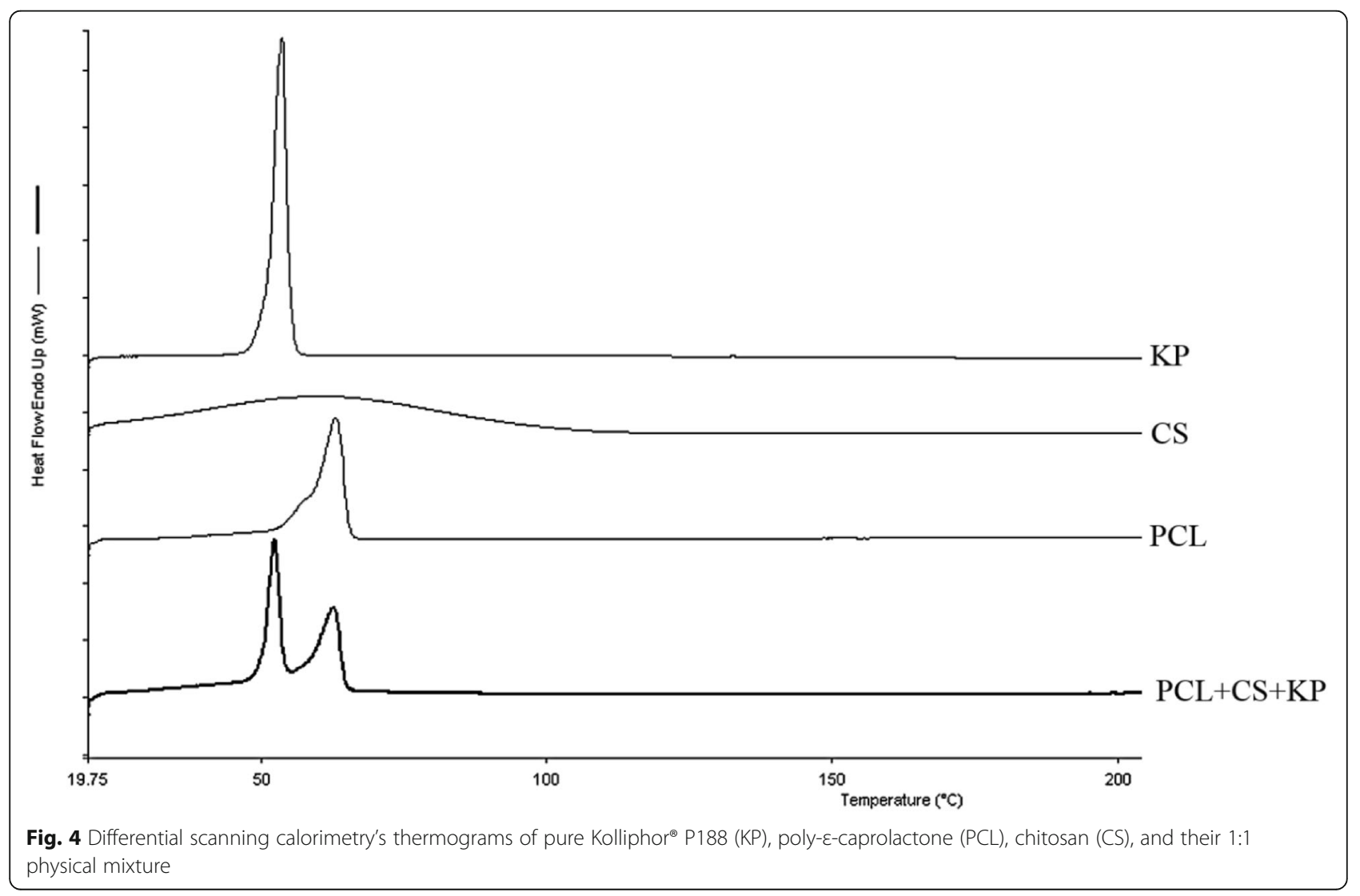



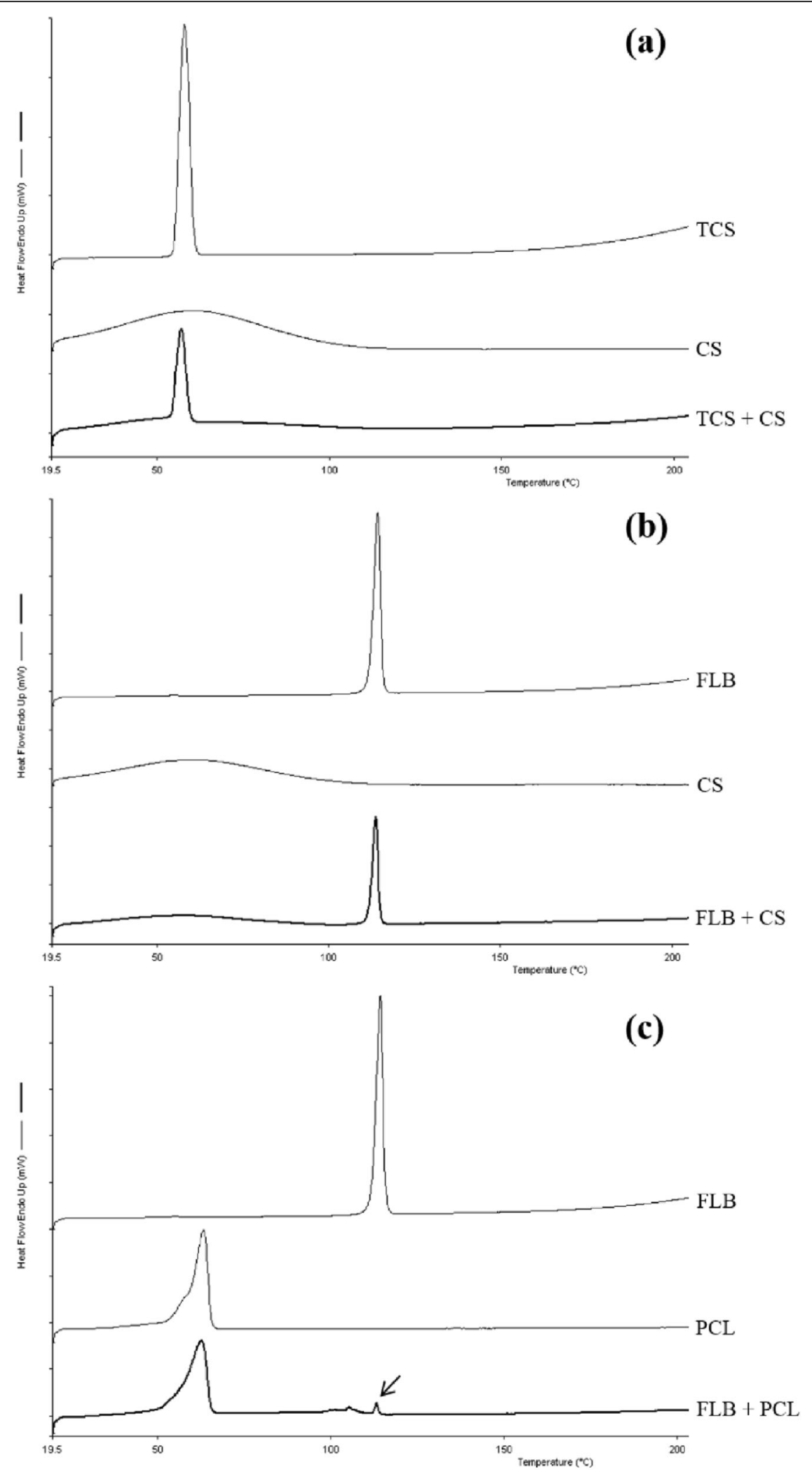

Fig. 5 Differential scanning calorimetry's thermograms of 1:1 combination of $\mathbf{a}$ triclosan with chitosan, $\mathbf{b}$ flurbiprofen with chitosan, and $\mathbf{c}$ flurbiprofen with poly- $\varepsilon$-caprolactone, along with their respective individual pure components for comparison. The arrow indicated a small peak of flurbiprofen (FLB) which decreased due to the dilution effect of the physical mixture 


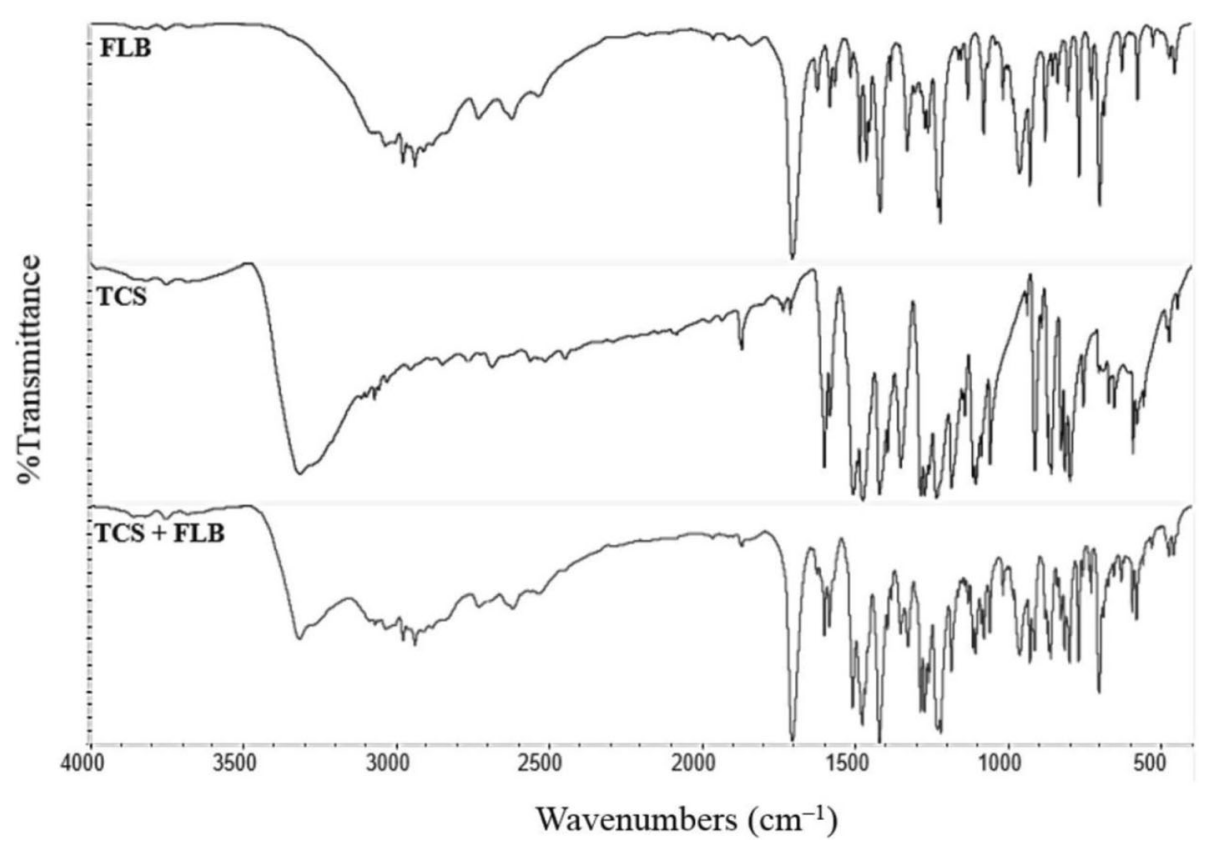

Fig. 6 Fourier transform infrared spectroscopy's spectra of 1:1 w/W physical mixture of triclosan (TCS) and flurbiprofen (FLB), and their respective pure forms

The FTIR spectra of physical mixtures of FLB + CS and TCS + CS (Fig. 8A) and PCL + CS + KP (Fig. 8B) were a simple superimposition of their pure components, thus indicating a lack of interactions. It is important to note that some observed absorption bands of drugs and excipients in the range of $3800-2800 \mathrm{~cm}^{-1}$ which were mainly due to $\mathrm{O}-\mathrm{H}$, $\mathrm{C}-\mathrm{H}, \mathrm{C}-\mathrm{CH}_{3}$, and $\mathrm{CH}_{2}$ groups, and $\mathrm{NH}_{2}$ group (in the case of CS) are overlapped. Similarly, the spectra of a physical mixture of drugs and excipients showed characteristic absorption bands of pure TCS, FLB, PCL, CS, and KP (Fig. 8C).

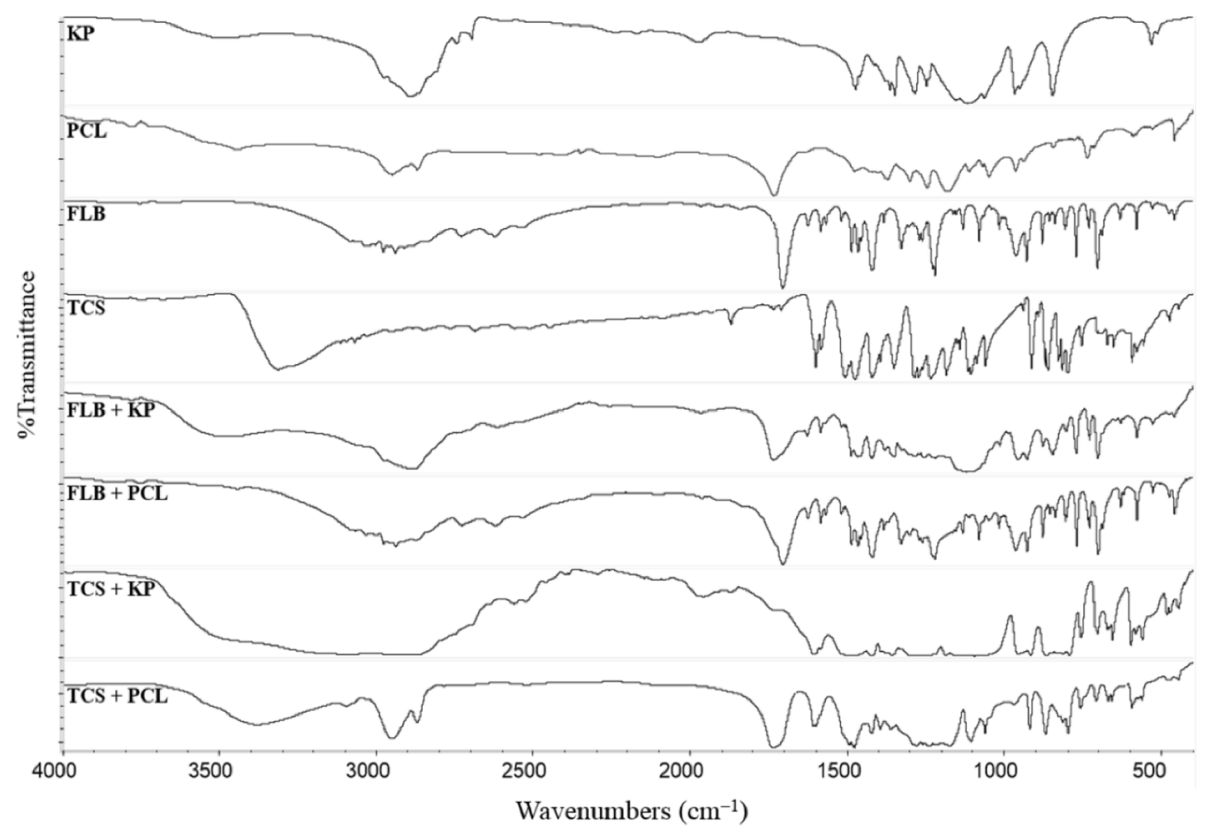

Fig. 7 Fourier transform infrared spectroscopy's spectra of 1:1 W/W physical mixture of flurbiprofen (FLB) with Kolliphor P188 (KP) and poly- $\varepsilon-$

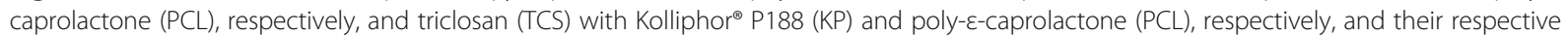
pure forms 

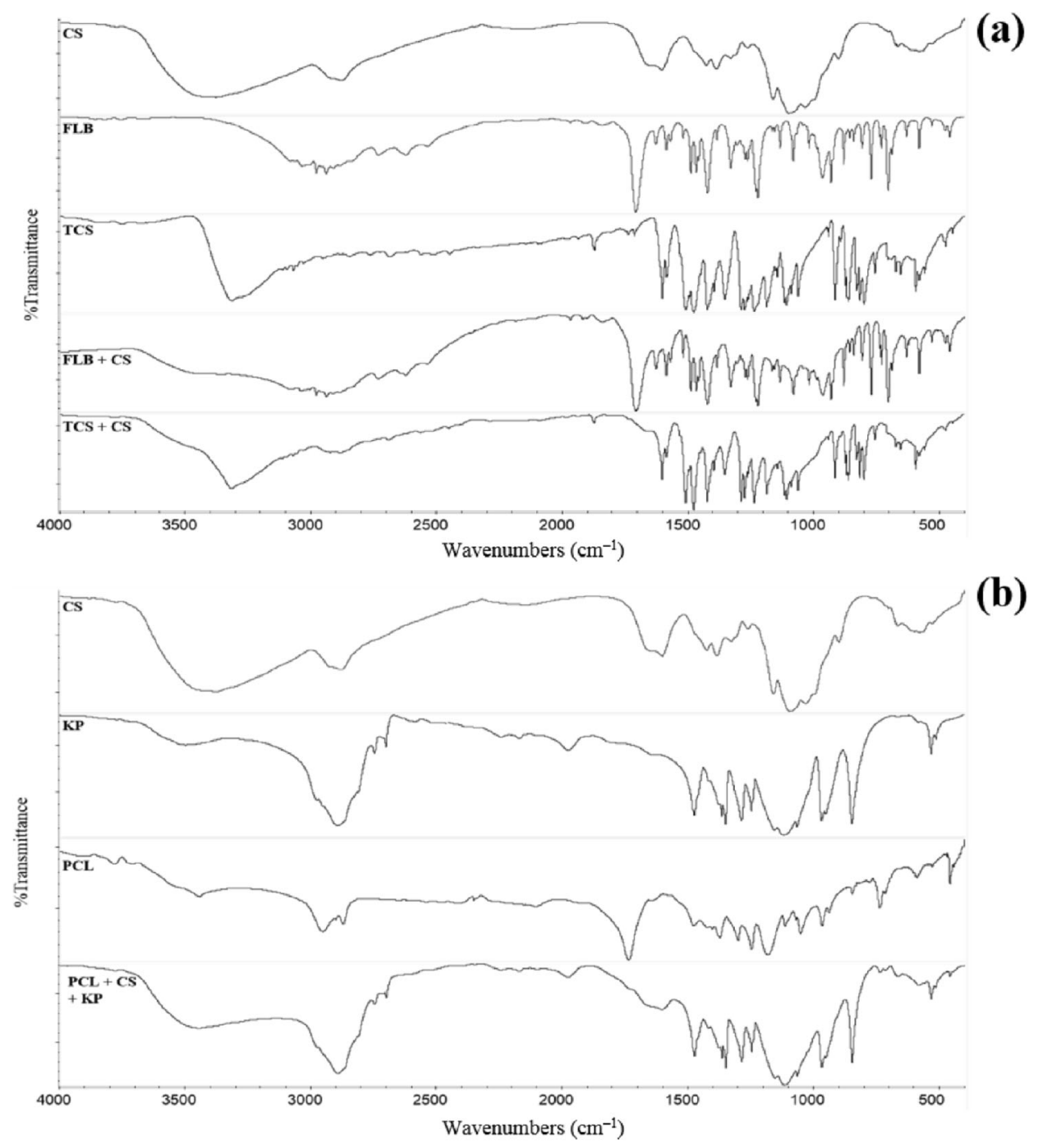

(b)

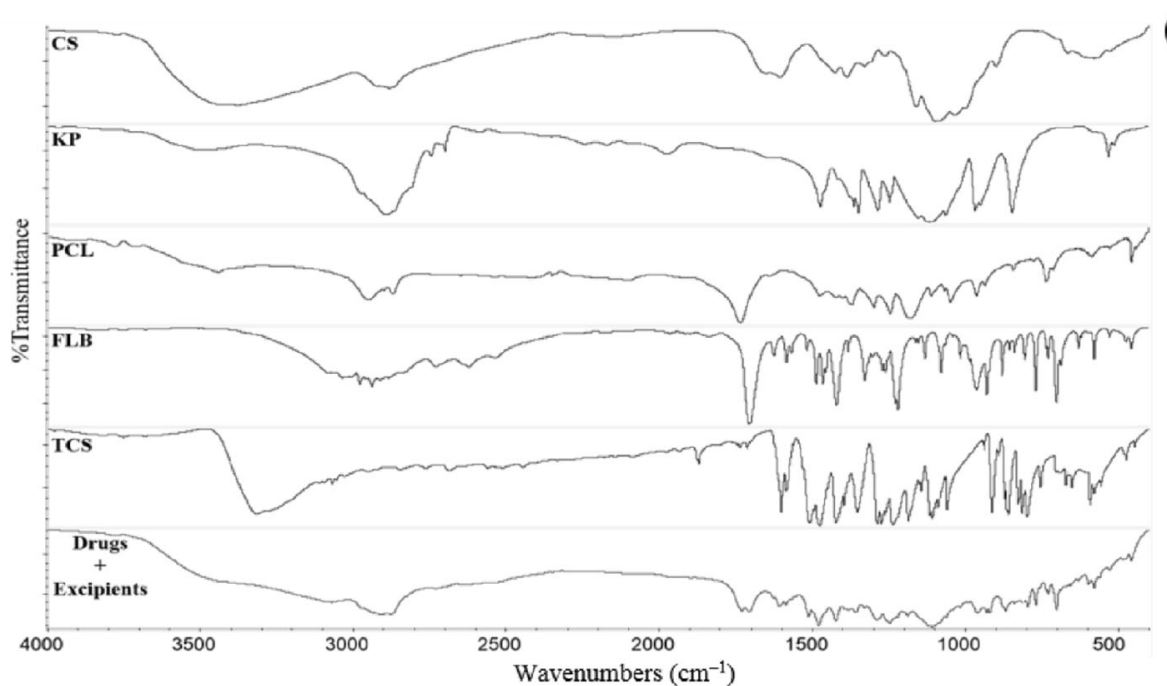

Fig. 8 Fourier transform infrared spectroscopy's spectra of 1:1 w/w physical mixture of a chitosan (CS) with flurbiprofen (FLB) and with triclosan (TCS), and their respective pure forms; b poly- $\varepsilon$-caprolactone (PCL) and chitosan (CS) and Kolliphor ${ }^{\circledR}$ P188 (KP), and their respective pure forms; and (c) all drugs and excipients, and their respective pure forms 


\section{X-ray powder diffraction}

The X-ray powder diffraction patterns of the pure components (Fig. 9) of the present study showed major reflections at the $2 \theta$ at $7.3,10.9,15.9,20.7,21.6,23.8$, and $29.7^{\circ}$ for FLB; at $8.2,14.1,15.5,16.3,21.6,24.5,25.3$, and $29.5^{\circ}$ for TCS; at 19.1 and $23.2^{\circ}$ for KP; and at 21.5 and $23.8^{\circ}$ for PCL.

The XRPD of 1:1 w/w physical mixture of TCS and FLB (Fig. 9) presents all the major diffraction peaks of both APIs. Similarly, the XRPD patterns of the other physical mixtures reflected all the signature reflexes like those of their respective individual pure components.
Furthermore, the diffraction patterns of drugs-excipients mixture, i.e., all the components together (Fig. 9) showed essential peaks exhibited by both API and excipients alone, especially the signature reflexes that confirm the identity of the respective components at diffraction angles of $2 \theta=15.4$, 24.4, 25.4, and 29.5 (TCS); 7.2, 10.9, 15.6, 20.3, and $29.7^{\circ}$ (FLB); 21.5 and $23.9^{\circ}(\mathrm{PCL})$; and 19.1 and $23.2^{\circ}(\mathrm{KP})$.

\section{Scanning electron microscopy}

SEM photomicrographs of TCS (Fig. 10A) and FLB (Fig. 10B) demonstrated that the shape of the particles of both

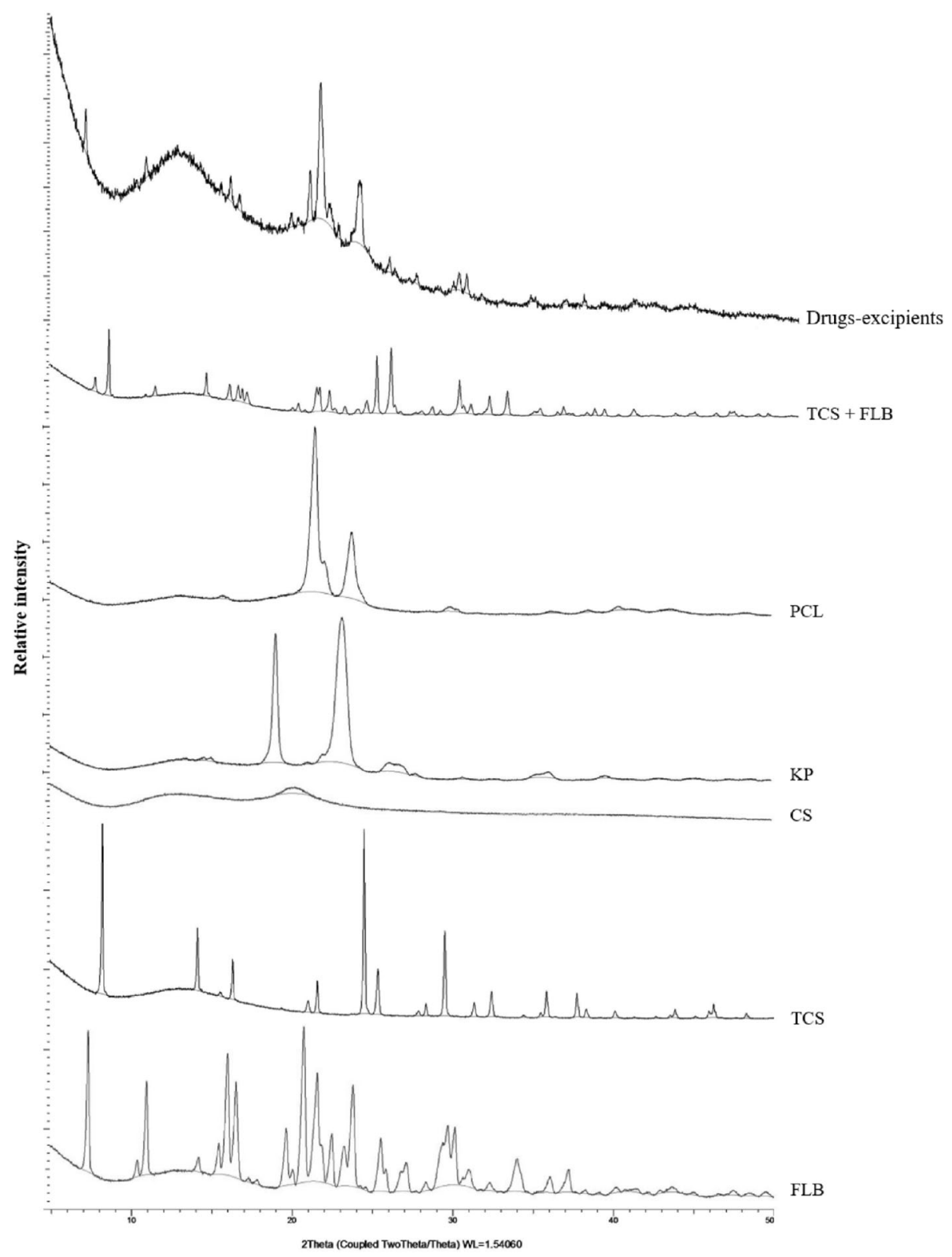

Fig. 9 X-ray powder diffraction patterns of pure components of the present study, namely flurbiprofen (FLB), triclosan (TCS), chitosan (CS),

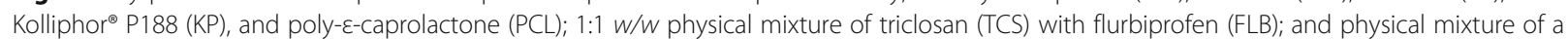
combination of all drugs with excipients of the present study 


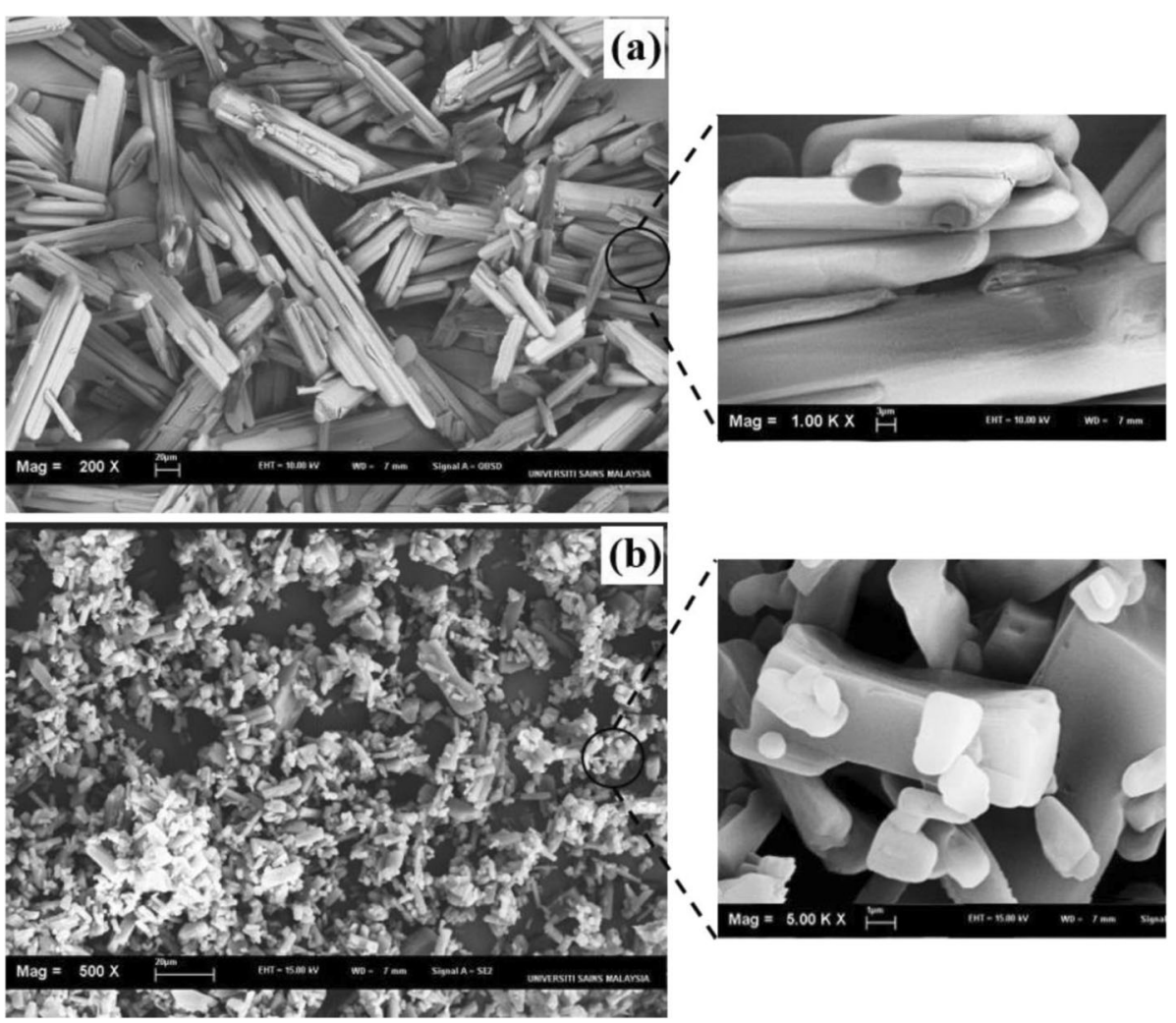

Fig. 10 Scanning electron microscopy's photomicrograph of a triclosan at 200x and 1000x magnifications; b flurbiprofen at 500× and 5000× magnifications

APIs is crystalline, as stated in the United States Pharmacopeia (USP) [34]. It was observed that the particles of TCS are rhombohedral crystals (Fig. 10A), which clearly differed from that observed for FLB, which revealed irregular and mostly orthorhombic crystals (Fig. 10B).

\section{High-performance liquid chromatography}

The drug content results are presented in Table 1. For assessing the compatibility, chromatograms of the mixtures were compared with that of the pure components. The chromatograms of the mixtures (Fig. 11) showed a clear separation of the respective components' peaks, with no addition of peaks that could be associated with degradation products. An overlap of retention time $\left(t_{\mathrm{R}}\right)$ peaks was observed for the PCL with KP mixture, which was expected since there is only about $0.1 \mathrm{~min}$ difference between their $t_{\mathrm{R}}$. However, this overlap did not interfere with the separation of other components or assay of the drugs.

The recoveries and \% RSD of all the mixtures with drug content were in the range of 97.0 to $101.8 \%$ and 0.2 to 1.6 , respectively, which are very much in agreement with that of the respective pure drugs, and also conformed with the assay criterion [62]. Moreover, the established peaks' parameters (sharpness and symmetry) and $t_{\mathrm{R}}$ at 10.1 and $12.5 \mathrm{~min}$ for FLB and TCS, respectively, were well maintained, thus corroborating the results of FTIR and XRPD, as well as confirming the compatibility of the selected components.

\section{Discussion}

We carried out compatibility screening based on binary or multiple combination mixtures of the drugs, namely TCS and FLB, with polymers, namely PCL, CS, and KP, to assess their suitability for the development of pharmaceutical nano-formulations.

The visual observations of the samples suggested absence of incompatibility between the selected drugs and excipients as no significant visual changes were observed.

The DSC results revealed that TCS, FLB, and KP exhibited sharp endothermic peaks that are attributable to their respective melting points and indicated their existence in crystalline forms. PCL showed a reasonably sharp melting peak with a moderately broad endothermal effect, suggesting its existence as semi-crystalline substance. CS showed a wide endotherm due to the dehydration process of bound water and its amorphous nature, and this was in agreement with the reported data $[20,38,39]$. The observed broadening, overlapping and shift of peaks toward the lower temperatures, and disappearance of melting peak of FLB in the drugsexcipients physical mixture may suggests the occurrence of some physical interaction but not necessarily an 


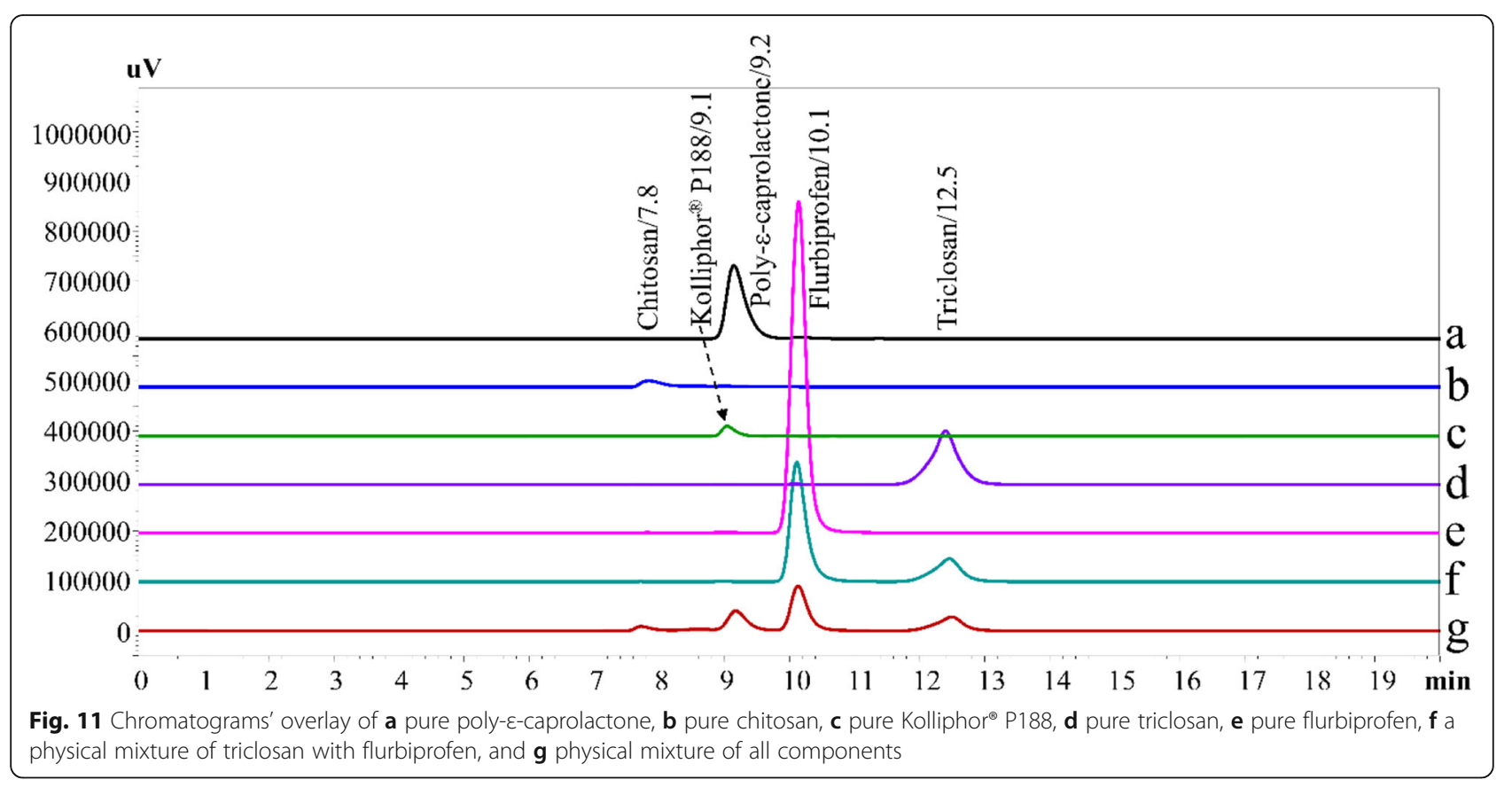

incompatibility. This phenomenon could be as a result of mixing of the components together which in turn reduces their purity and hence their thermal behavior [ 55 , 63, 64]. Another reason for the disappearance of FLB melting peak could be due to its dissolution in the melted TCS, PCL, and KP which have lower melting points than the drug $[55,65]$. The shape of DSC peaks and enthalpy may change as a result of a change in the purity of materials under analysis [63]. Therefore, all the observed changes in the endothermic melting peaks could be due to the mixing effect between the components which alter their purity in the mixture and may not necessarily indicate potential incompatibility $[15$, 63]. However, further analytical investigation such as FTIR is warranted to prove whether any chemical interaction occurred.

FTIR spectroscopy is an essential analytical technique covering a wide range of chemical applications such as compound identification and chemical process monitoring. The technique can discriminate materials according to their type, and it is commonly employed in compatibility screening of APIs with excipients [18, 19, 28, 64]. FTIR spectroscopy study was conducted to find out more information of the physical mixtures and to support the DSC results. All the essential absorption bands for both TCS and FLB in their fingerprint regions were well retained in the FTIR spectra of the physical mixture of the drugs (Fig. 6), thus confirming their compatibility. Contrary to the DSC results which pointed out possible interaction in some mixtures such as FLB + KP, FLB + PCL, TCS + PCL, and TCS + KP, the FTIR profile of these combinations (Fig. 7) reveals characteristic bands of each component. The minor observed changes in these other mixtures, such as intensity reduction, broadening, or slight shift of peaks, may be due to the mixing and dilution effects [27]. An overlap of some peaks was due to location similarity in the same spectral regions. For example, the $\mathrm{C}=\mathrm{O}$ sharp peak of PCL at $1728 \mathrm{~cm}^{-1}$ has disappeared due to overlapping with the $\mathrm{N}-\mathrm{H}$ bonds (amide group) bending vibrations between 1700 and $1600 \mathrm{~cm}^{-1}$ [18]. But there was no observed significant change in the absorption bands that corresponded to specific moieties of the individual components of the physical mixtures. There was no appearance of new bands in the spectra of the mixtures, indicating lack of any significant structural changes in all the selected components. Similar observations were reported by Rojek and Wesolowski [66] and Meira and coworkers [21] for their drug-excipients compatibility studies. Rojek and Wesolowski [18] also reported an overlap of absorption bands of excipient (chitosan) and API (atenolol) in the range of $1700-400 \mathrm{~cm}^{-1}$. Therefore, based on the above FTIR results, the selected components were found to be compatible with each other, thus there were no chemical incompatibilities in drug-drug/drug-excipient combinations.

The results of XRPD confirmed the solid-state of all the components, where both APIs were found to be crystalline, PCL and KP were found to be semicrystalline, while CS was an amorphous solid. Similar diffraction patterns were obtained by other researchers for TCS [56], KP [37], FLB, and PCL [60, 67]. Pure CS showed an amorphous XRPD pattern due to its amorphous nature [68], which was maintained in all of its 
mixtures with other components. The physical mixture of all the samples (Fig. 9) showed all the major diffraction peaks of each component, thus indicating lack of solid-state interaction between them. The decreased intensity of peaks was attributed to the dilution effect. These XRPD results have suggested compatibility between the selected drugs and excipients for the present study and confirmed the FTIR result.

SEM was performed to examine the physical state of the selected APIs and both of them apparently appeared as crystalline solids, confirming the DSC and XRPD results. HPLC analysis was conducted for all the mixtures with API content to corroborate the DSC, FTIR, and XRPD data and the results confirmed the compatibility of the selected components.

A limitation of this study is the samples' storage period that was only 30 days. Although 30 days period or less was reported for similar studies in the literature $[1,17$, $20,63]$, a longer storage period could possibly reveal potential interaction that may occur between the selected components if such exist. Moreover, this study did not involve moisture, hence no revelation on the interaction that may exist under moisture condition. Therefore, it will also be interesting to investigate the compatibility of the tested components by isothermal stress testing method, i.e., under moisture condition and at elevated temperature $\left(50{ }^{\circ} \mathrm{C}\right)$.

\section{Conclusion}

For selecting suitable and compatible APIs and excipients for the development of pharmaceutical formulation, drug-drug/drug-excipient/drugs-excipients/excipient-excipient compatibility studies were performed. APIs (TCS and FLB) and excipients (PCL, CS, and KP) compatibility studies were carried out for their physical mixtures by visual observations, DSC, FTIR, XRPD, and HPLC. Following the storage period, the data of TCS and FLB showed that both drugs are crystalline substances, as reported in USP [34], with a well-defined fusion peak in their DSC curves and sharp X-ray diffraction patterns that were further confirmed by SEM images. PCL exhibited semi-crystalline characteristics in both DSC and XRPD data, while KP revealed a sharp peak in the DSC curve and semi-crystalline behavior in the X-ray diffraction patterns, as previously reported in the literature [36, 37]. Data from DSC and XRPD confirmed the amorphous nature of CS, as reported [38, 68]. These results indicated that the evaluated components did not undergo any physical changes during the study period. HPLC analysis revealed satisfactory recovery of APIs from all mixtures and their clear separation from excipients. The combination of components has not shown any significant physical and chemical instability. Therefore, the results of DSC, FTIR, XRPD, and HPLC studies ruled out incompatibility between all the selected components, hence, could be used for the development of pharmaceutical formulations, especially nano-formulation.

\section{Abbreviations}

TCS: Triclosan; FLB: Flurbiprofen; PCL: Poly-e-caprolactone; CS: Chitosan; KP: Kolliphor ${ }^{\circledast}$ P188; DSC: Differential scanning calorimetry; FTIR: Fourier transform infrared spectroscopy; XRPD: X-ray powder diffraction;

SEM: Scanning electron microscopy; APIs: Active pharmaceutical ingredients; HPLC: High-performance liquid chromatography; NMR: Nuclear magnetic resonance; NSAIDs: Non-steroidal anti-inflammatory drugs; KBr: Potassium bromide; $\Delta H_{\text {fus: }}$ : Enthalpy; $T_{\text {onset }}$ : Onset temperature; USP: United States Pharmacopeia; $t_{\mathrm{R}}$ : Retention time

\section{Acknowledgements}

The authors thank Universiti Sains Malaysia (USM) for providing some facilities to conduct this work.

\section{Authors' contributions}

Conceptualization, investigation, and writing, NA, SYC, and MAM; methodology, validation, and formal analysis, NA, SMT, NMU, and AA; data curation, NT and SAZ; visualization, NA, SAZ, and NMU; resources, NA, SMT, MAM, NT, and AA. All authors have critically reviewed and approved the final submission of the manuscript.

\section{Funding}

The study was done with the financial support from Usmanu Danfodiyo University, Sokoto, Nigeria.

\section{Availability of data and materials}

Data and materials are available upon request.

\section{Declarations}

Ethics approval and consent to participate Not applicable.

\section{Consent for publication}

Not applicable.

\section{Competing interests}

The authors declare that they have no competing of interests.

\section{Author details}

${ }^{1}$ Department of Pharmaceutics and Pharmaceutical Microbiology, Faculty of Pharmaceutical Sciences, Usmanu Danfodiyo University, P.M.B, Sokoto 2346, Nigeria. ${ }^{2}$ Discipline of Pharmaceutical Technology, School of Pharmaceutical Sciences, Universiti Sains Malaysia, 11800 USM, Penang, Malaysia.

${ }^{3}$ Department of Pharmaceutics, Faculty of Pharmaceutical Sciences,

University of Nigeria, Nsukka, Nigeria. ${ }^{4}$ Department of Pure and Applied Chemistry, Faculty of Science, Usmanu Danfodiyo University, P.M.B, Sokoto 2346, Nigeria. ${ }^{5}$ Department of Pure and Industrial Chemistry, Faculty of Science, Federal University Birnin Kebbi, PMB, Birnin Kebbi 1157, Nigeria.

Received: 10 April 2021 Accepted: 5 July 2021

Published online: 22 July 2021

\section{References}

1. Dinte E, Bodoki E, Leucuta S, luga CA (2013) Compatibility studies between drugs and excipients in the preformulation phase of buccal mucoadhesive systems. Farmacia 61:703-712

2. da S GJ, Freire FD, de LE MTFA, CFS A, Raffin FN (2019) Preformulation of a liquid dosage formulation of captopril for pediatric use: drug-excipient compatibility and stability studies. Brazilian J Pharm Sci 55:1-10

3. Thapa RK, Winther-Larsen HC, Diep DB, Tønnesen HH (2020) Preformulation studies on novel garvicin KS peptides for topical applications. Eur J Pharm Sci 151:105333. https://doi.org/10.1016/j.ejps.2020.105333

4. Pezik E, Gulsun T, Sahin S, Vural I (2021) Development and characterization of pullulan-based orally disintegrating films containing amlodipine besylate. Eur J Pharm Sci 156:105597. https://doi.org/10.1016/j.ejps.2020.105597 
5. Jain A, Hu G, Kumar Ratnakaram SS, Johnson DK, Picking WD, Picking WL, Middaugh CR (2021) Preformulation characterization and the effect of ionic excipients on the stability of a novel DB fusion protein. J Pharm Sci 110(1): 108-123. https://doi.org/10.1016/j.xphs.2020.09.008

6. Bharate SS, Bharate SB, Bajaj AN (2010) Interactions and incompatibilities of pharmaceutical excipients with active pharmaceutical ingredients: a comprehensive review. J Excipients Food Chem 1:3-26

7. Chadha R, Bhandari S (2014) Drug-excipient compatibility screening-role of thermoanalytical and spectroscopic techniques. J Pharm Biomed Anal 87: 82-97. https://doi.org/10.1016/j.jpba.2013.06.016

8. Zhang L, Luan H, Lu W, Wang H (2020) Preformulation studies and enabling formulation selection for an insoluble compound at preclinical stage-from in vitro, in silico to in vivo. J Pharm Sci 109(2):950-958. https://doi.org/10.1 016/j.xphs.2019.10.023

9. Patel P, Ahir K, Patel V, Manani L, Patel C (2015) Drug-Excipient compatibility studies : First step for dosage form development. Pharma Innov J 4:14-20

10. Shahe M, Chetty M, Ramana Murthy K (2012) Compatibility studies between propafenone and selected excipients used in the development of controlled release formulations. Asian J Pharm 6(2):144-150. https://doi. org/10.4103/0973-8398.102939

11. Júlio TA, Zâmara IF, Garcia JS, Trevisan MG (2013) Compatibility of sildenafil citrate and pharmaceutical excipients by thermal analysis and LC-UV. J Therm Anal Calorim 111(3):2037-2044. https://doi.org/10.1007/s10973012-2292-8

12. Pop AL, Crișan S, Bârcă M, Ciobanu AM, Varlas VN, Pop C, Pali MA, Cauni D, Ozon EA, Udeanu D, Trifu S, Năsui BA (2021) Evaluation of dissolution profiles of a newly developed solid oral immediate-release formula containing alpha-lipoic acid. Processes 9:1-22

13. Lopes MS, Catelani TA, Nascimento ALCS, Garcia JS, Trevisan MG (2020) Ketoconazole: compatibility with pharmaceutical excipients using DSC and TG techniques. J Therm Anal Calorim 141(4):1371-1378. https://doi.org/10.1 007/s10973-019-09137-0

14. Gupta KR, Pounikar AR, Umekar MJ (2019) Drug excipient compatibility testing protocols and charaterization: a review. Asian J Chem Sci 6:1-22

15. Thumma S, Repka MA (2009) Compatibility studies of promethazine hydrochloride with tablet excipients by means of thermal and non-thermal methods. Pharmazie 64(3):183-189

16. Bruni G, Amici L, Berbenni V, Marini A, Orlandi A (2002) Drug-excipient compatibility studies: search of interaction indicators. J Therm Anal Calorim 68(2):561-573. https://doi.org/10.1023/A:1016052121973

17. Chidambaram M, Krishnasamy K (2014) Drug-drug/drug-excipient compatibility studies on curcumin using non-thermal methods. Adv Pharm Bull 4(3):309-312. https://doi.org/10.5681/apb.2014.045

18. Rojek B, Wesolowski M (2016) Fourier transform infrared spectroscopy supported by multivariate statistics in compatibility study of atenolol with excipients. Vib Spectrosc 86:190-197. https://doi.org/10.1016/j.vibspec.2016. 07.011

19. Liltorp K, Larsen TG, Willumsen B, Holm R (2011) Solid state compatibility studies with tablet excipients using non thermal methods. J Pharm Biomed Anal 55(3):424-428. https://doi.org/10.1016/j.jpba.2011.02.016

20. Pramod K, Suneesh CV, Shanavas S, Ansari SH, Ali J (2015) Unveiling the compatibility of eugenol with formulation excipients by systematic drugexcipient compatibility studies. J Anal Sci Technol 6(1):34. https://doi.org/1 0.1186/s40543-015-0073-2

21. Meira RZC, Biscaia IFB, Nogueira C, Murakami FS, Bernardi LS, Oliveira PR (2019) Solid-state characterization and compatibility studies of Penciclovir, lysine hydrochloride, and pharmaceutical excipients. Materials (Basel) 12:1-14

22. Saraf I, Modhave D, Kushwah V, Neshchadin D, Gescheidt G, Trausinger G, Melchior P, Magnes C, Paudel A (2020) Feasibility of rapidly assessing reactive impurities mediated excipient incompatibility using a new method: a case study of famotidine-PEG system. J Pharm Biomed Anal 178:112893. https://doi.org/10.1016/j.jpba.2019.112893

23. Li Y, Kong X, Hu F (2020) Crystal transition and drug-excipient compatibility of clarithromycin in sustained release tablets. Curr Pharm Anal 16(7):950959. https://doi.org/10.2174/1573412915666190328234326

24. Aminu N, Bello I, Umar NM, Tanko N, Aminu A, Audu MM (2020) The influence of nanoparticulate drug delivery systems in drug therapy. J Drug Deliv Sci Technol 60:101961. https://doi.org/10.1016/j.jddst.2020.101961

25. Gallo LC, Gonzalez Vidal NL, Ferreira FF, Ramírez-Rigo MV (2021) Sulbactam pivoxil powder attributes and compatibility study with excipients. Futur J Pharm Sci 7:1-8
26. Sahu RS, Jain D (2020) Compatibility studies of montelukast with pharmaceutical excipients used in tablet formulations using thermal and chromatographic techniques. J Bioanal Biomed 12:1-10

27. Mora PC, Cirri M, Mura P (2006) Differential scanning calorimetry as a screening technique in compatibility studies of DHEA extended release formulations. J Pharm Biomed Anal 42(1):3-10. https://doi.org/10.1016/j. jpba.2006.02.038

28. Daniel JSP, Veronez IP, Rodrigues LL, Trevisan MG, Garcia JS (2013) Risperidone - Solid-state characterization and pharmaceutical compatibility using thermal and non-thermal techniques. Thermochim Acta 568:148-155. https://doi.org/10.1016/j.tca.2013.06.032

29. Aminu N, Chan SY, Khan NH, Farhan AB, Umar MN, Toh SM (2019) A simple stability-indicating HPLC method for simultaneous analysis of paracetamol and caffeine and its application to determinations in fixed-dose combination tablet dosage form. Acta Chromatogr 31(2):85-91. https://doi. org/10.1556/1326.2018.00354

30. Dadge S, Rao J (2019) Compatibility study between bosentan and pharmaceutical excipients used in solid dosage forms. Curr Trends Pharm Pharm Chem 1:61-77

31. Osman Z, Farah Y, Ali Hassan H, Elsayed S (2021) Comparative physicochemical evaluation of starch extracted from pearl millet seeds grown in sudan as a pharmaceutical excipient against maize and potato starch, using paracetamol as a model drug. Ann Pharm Françaises 79(1):2835. https://doi.org/10.1016/j.pharma.2020.08.004

32. Santos WM, Nóbrega FP, Andrade JC, Almeida LF, Conceição MM, Medeiros ACD, Medeiros FD (2020) Pharmaceutical compatibility of dexamethasone with excipients commonly used in solid oral dosage forms. J Therm Anal Calorim. 145(2):361-378. https://doi.org/10.1007/s10973-020-09753-1

33. Niguram P, Polaka SN, Rathod R, Kalia K, Kate AS (2020) Update on compatibility assessment of empagliflozin with the selected pharmaceutical excipients employed in solid dosage forms by thermal, spectroscopic and chromatographic techniques. Drug Dev Ind Pharm 46(2):209-218. https:// doi.org/10.1080/03639045.2020.1716371

34. United States Pharmacopeia (2007) The United States Pharmacopeia: USP 30: the National Formulary: NF 25. United States Pharmacopeial Convention, Washington, D.C.

35. Ramanujam R, Sundaram B, Janarthanan G, Devendran E, Venkadasalam M, John Milton MC (2018) Biodegradable polycaprolactone nanoparticles based drug delivery systems: a short review. Biosci Biotechnol Res Asia 15(3):679685. https://doi.org/10.13005/bbra/2676

36. Nevoralová M, Koutný M, Ujčić A, Starý Z, Šerá J, Vlková H, Šlouf M, Fortelný I, Kruliš Z (2020) Structure characterization and biodegradation rate of poly( $\varepsilon$-caprolactone)/starch blends. Front Mater 7:1-14

37. Ramadhani N, Shabir M, McConville C (2014) Preparation and characterisation of Kolliphor P 188 and P 237 solid dispersion oral tablets containing the poorly water soluble drug disulfiram. Int J Pharm 475(1-2): 514-522. https://doi.org/10.1016/j.jpharm.2014.09.013

38. Khan G, Yadav SK, Patel RR, Nath G, Bansal M, Mishra B (2016) Development and evaluation of biodegradable chitosan films of metronidazole and Levofloxacin for the management of periodontitis. AAPS PharmSciTech 17(6):1312-1325. https://doi.org/10.1208/s12249-015-0466-y

39. El-Hefian EA, Nasef MM, Yahaya AH (2011) Preparation and characterization of chitosan/poly(vinyl alcohol) blended films: mechanical, thermal and surface investigations. E-Journal Chem 8(1):91-96. https://doi.org/10.1155/2 011/969062

40. Aminu N, Baboota S, Pramod K, Singh M, Dang S, Ansari SH, Sahni JK, Ali J

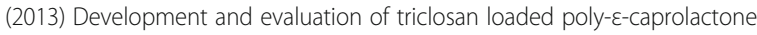
nanoparticulate system for the treatment of periodontal infections. J Nanoparticle Res 15(11):2075. https://doi.org/10.1007/s11051-013-2075-6

41. Piñón-Segundo E, Ganem-Quintanar A, Alonso-Pérez V, Quintanar-Guerrero D (2005) Preparation and characterization of triclosan nanoparticles for periodontal treatment. Int J Pharm 294(1-2):217-232. https://doi.org/10.101 6/j.jpharm.2004.11.010

42. Ciancio SG (2007) Encyclopedia of Pharmaceutical Technology, 3rd edn. Informa Healthcare USA, Inc., New York

43. Davies RM (2007) The clinical efficacy of triclosan/copolymer and other common therapeutic approaches to periodontal health. Clin Microbiol Infect 13:25-29. https://doi.org/10.1111/j.1469-0691.2007.01801.x

44. Ribeiro FV, Barrella GE, Casarin RCV, Cirano FR, Foglio MA, Pimentel SP (2012) Effect of crude extract and essential oil of Cordia verbenacea in experimental periodontitis in rats. Brazilian J Oral Sci 11:42-46 
45. Heasman PA, Benn DK, Kelly PJ, Seymour RA, Aitken D (1993) The use of topical flurbiprofen as an adjunct to non-surgical management of periodontal disease. J Clin Periodontol 20(6):457-464. https://doi.org/1 0.1111/j.1600-051X.1993.tb00389.x

46. Hersh EV, Hammond BF, Fleury AA (1991) Antimicrobial activity of flurbiprofen and ibuprofen in vitro against six common periodontal pathogens. J Clin Dent 3(1):1-5

47. Jeffcoat MK, Reddy MS, Haigh S, Buchanan W, Doyle MJ, Meredith MP Nelson SL, Goodale MB, Wehmeyer KR (1995) A comparison of topical ketorolac, systemic flurbiprofen, and placebo for the inhibition of bone loss in adult periodontitis. J Periodontol 66(5):329-338. https://doi.org/10.1902/ jop.1995.66.5.329

48. Aminu N, Yam MF, Chan SY, Bello I, Umar NM, Nuhu T, Toh SM (2020) The evaluation of healing effect of triclosan and flurbiprofen-loaded nanogels in experimental periodontitis in rats by morphometric analysis. Saudi Dent J. https://doi.org/10.1016/j.sdentj.2020.08.008

49. Aminu N, Chan SY, Toh SM (2017) Roles of nanotechnological approaches in periodontal disease therapy. J Appl Pharm Sci 7:234-242

50. Aminu N, Toh SM (2017) Applicability of nanoparticles-hydrogel composite in treating periodontal diseases and beyond. Asian J Pharm Clin Res 10(2): 65-70. https://doi.org/10.22159/ajpcr.2017.v10i2.15709

51. Pramod K, Aminu N, Ali J (2014) Targeted drug delivery systems for the treatment of periodontal infections. In: Singh B, Katare OP, Govil JN (eds) Biotechnol. Vol. 8 Nov. Drug Deliv. Studium Press LLC, U.S.A., pp 97-128

52. Aminu N, Chan SY, Toh SM (2018) Development and validation of a stability-indicating HPLC-UV method for the simultaneous determination of flurbiprofen and triclosan in dental nanogel formulations. J Phys Sci 29(Suppl. 1):1-7. https://doi.org/10.21315/jps2018.29.s1.1

53. Aminu N, Chan SY, Yam MF, Toh SM (2019) A dual-action chitosan-based nanogel system of triclosan and flurbiprofen for localised treatment of periodontitis. Int J Pharm 570:118659. https://doi.org/10.1016/j.jpharm.201 9.118659

54. Aminu N, Chan SY, Khan NH, Toh SM (2018) Concurrent determination of triclosan and flurbiprofen by high-performance liquid chromatography in simulated saliva and its application in dental nanogel formulation. Acta Chromatogr 30(4):219-224. https://doi.org/10.1556/1326.2017.00286

55. Mura P, Manderioli A, Bramanti G, Furlanetto S, Pinzauti S (1995) Utilization of differential scanning calorimetry as a screening technique to determine the compatibility of ketoprofen with excipients. Int J Pharm 119(1):71-79. https://doi.org/10.1016/0378-5173(94)00374-E

56. Celebioglu A, Umu OCO, Tekinay T, Uyar T (2014) Antibacterial electrospun nanofibers from triclosan/cyclodextrin inclusion complexes. Colloids Surfaces B Biointerfaces 116:612-619. https://doi.org/10.1016/j.colsurfb.2 013.10 .029

57. Davachi SM, Kaffashi B (2015) Preparation and characterization of Poly Llactide/triclosan nanoparticles for specific antibacterial and medical applications. Int J Polym Mater Polym Biomater 64(10):497-508. https://doi. org/10.1080/00914037.2014.977897

58. Orhan M (2012) Polietilen Tereftalat Liflerindeki Triklosanın Belirlenmesi ve Karakterizasyonu. J Text Eng 19:27-30

59. Sohail MF, Shah PA, Tariq I, Saeed-ul-Hassan S, Amin U, Raza SA, Saeed T, Sultana M, Jawa H (2014) Development and in vitro evaluation of flurbiprofen microcapsules prepared by modified solvent evaporation technique. Trop J Pharm Res 13(7):1031-1038. https://doi.org/10.4314/tjpr. v13i7.4

60. Ranjha NM, Khan IU, Naseem S (2009) Encapsulation and characterization of flurbiprofen loaded poly(e-caprolactone)-poly(vinylpyrrolidone) blend micropheres by solvent evaporation method. J Sol-Gel Sci Technol 50(3): 281-289. https://doi.org/10.1007/s10971-009-1957-7

61. Ramesh K, Shekar BC, Khadgapathi P, Bhikshapathi DVR, Gourav N (2015) Enhancement of solubility and bioavailability of etravirine solid dispersions by solvent evaporation technique with novel carriers. IOSR J Pharm Biol Sci 10:30-41

62. Shabir GA (2003) Validation of high-performance liquid chromatography methods for pharmaceutical analysis: Understanding the differences and similarities between validation requirements of the US Food and Drug Administration, the US Pharmacopeia and the International Conf. J Chromatogr A 987(1-2):57-66. https://doi.org/10.1016/S0021-9673(02)01536-4

63. Pani NR, Nath LK, Acharya S, Bhuniya B (2012) Application of DSC, IST, and FTIR study in the compatibility testing of nateglinide with different pharmaceutical excipients. J Therm Anal Calorim 108(1):219-226. https://doi org/10.1007/s10973-011-1299-x

64. Verma RK, Garg S (2005) Selection of excipients for extended release formulations of glipizide through drug-excipient compatibility testing. J Pharm Biomed Anal 38(4):633-644. https://doi.org/10.1016/j.jpba.2005.02.026

65. Chan SY, Toh SM, Khan NH, Chung YY, Cheah XZ (2016) The improved dissolution performance of a post processing treated spray-dried crystalline solid dispersion of poorly soluble drugs. Drug Dev Ind Pharm 42(11):18001812. https://doi.org/10.3109/03639045.2016.1173054

66. Rojek B, Wesolowski M (2019) FTIR and TG analyses coupled with factor analysis in a compatibility study of acetazolamide with excipients. Spectrochim Acta Part A Mol Biomol Spectrosc 208:285-293. https://doi. org/10.1016/j.saa.2018.10.020

67. Jayakumar $R$, Tamura $H$ (2008) Synthesis, characterization and thermal properties of chitin-g-poly( $(\varepsilon$-caprolactone) copolymers by using chitin gel. Int Biol Macromol 43(1):32-36. https://doi.org/10.1016/j.ijbiomac.2007.09.003

68. Ruiz-Caro R, Veiga-Ochoa MD (2009) Characterization and dissolution study of chitosan freeze-dried systems for drug controlled release. Molecules 14(11):4370-4386. https://doi.org/10.3390/molecules14114370

\section{Publisher's Note}

Springer Nature remains neutral with regard to jurisdictional claims in published maps and institutional affiliations.

\section{Submit your manuscript to a SpringerOpen ${ }^{\circ}$ journal and benefit from:}

- Convenient online submission

- Rigorous peer review

- Open access: articles freely available online

High visibility within the field

- Retaining the copyright to your article

Submit your next manuscript at $>$ springeropen.com 